\title{
Bilingualisme dalam Perspektif Pengembangan Bahasa Indonesia
}

\author{
Arif Izzak ${ }^{*}$
}

\begin{abstract}
Abstrak
Indonesia sebagai sebuah bangsa memiliki keragaman budaya dan bahasa yang sangat tinggi. Tingkat kemajemukan yang sangat tinggi ini tercermin dalam jumlah bahasa daerah yang dimiliki dan keragaman budaya adat istiadat suku bangsa yang mendiaminya. Indonesia memiliki lebih dari 700 bahasa daerah yang mewakili setiap kelompok etnis. Jumlah Bahasa daerah terbanyak terdapat di Papua, lebih dari 200 bahasa daerah hidup di tanah Papua. Di samping kekayaan bahasa daerah, masyarakat Indonesia juga memiliki bahasa Indonesia yang berfungsi sebagai bahasa persatuan yang dideklarasikan oleh seluruh komponen bangsa yang diwakili oleh kaum muda dari berbagai daerah pada tanggal 28 Oktober 1928 yang dikenal dengan peristiwa Sumpah Pemuda. Keputusan bahwa bahasa Indonesia merupakan satu-satunya bahasa nasional Indonesia sudah final bagi bangsa Indonesia.

Dalam konteks keragaman bahasa, masyarakat Indonesia paling tidak menguasai dua bahasa yaitu bahasa daerah sebagai identitas asal daerahnya dan bahasa Indonesia sebagai identitas nasional. Bahasa pertama yang mereka peroleh saat mereka masih kanak-kanak dan bahasa Indonesia yang mereka kuasai sejak dini menyebabkan masyarakat Indonesia secara umum termasuk masyarakat yang bilingual. Kondisi masyarakat bahasa yang demikian pada akhirnya menjadi tantangan tersendiri terutama bagi pengembangan bahasa Indonesia. Kebijakan politik bahasa nasional yang telah menempatkan bahasa daerah, bahasa Indonesia, dan bahasa asing pada fungsi, peran, dan kedudukan masing-masing pada praktiknya menjadi tidak mudah karena dinamika masyarakat bahasa yang bilingual.

Pengembangan bahasa Indonesia masih banyak menemui hambatan baik yang datang dari dalam bahasa itu sendiri maupun dari luar bahasa. Hambatan dari dalam bisa berupa sikap bahasa yang kurang positif yang ditunjukkan oleh para penuturnya dan hambatan dari luar bisa berupa pengaruh dari bahasa-bahasa lain yang dianggap memunyai status dan kedudukan lebih tinggi dan lebih penting.
\end{abstract}

Kata kunci: bilingualisme, masyarakat bahasa, ragam budaya

\footnotetext{
*) Sarjana Sastra, Pembantu Pimpinan pada Balai Bahasa Provinsi Jawa Timur
} 


\section{Pengantar}

Negara Indonesia dikenal sebagai negara kepulauan yang didiami oleh ratusan suku bangsa dengan latar belakang budaya dan bahasa yang berbeda. Disebut negara kepulauan karena lebih dari 17.000 pulau baik besar maupun kecil termasuk dalam wilayah kedaulatan Indonesia. Bahkan, Indonesia merupakan negara kepulauan terbesar di dunia. Penduduk Indonesia yang jumlahnya hampir mencapai 250 juta dengan wilayah Nusantara yang begitu luas menjadikan Indonesia sebagai negara yang diperhitungkan di dunia. Secara politis jumlah penduduk yang besar akan meningkatkan peran bangsa Indonesia di kancah internasional.

Dalam konteks

keindonesiaan berhimpunnya orang-orang yang berbeda latar belakang sosial budaya dan bahasa ke dalam negara kesatuan RI merupakan suatu anugerah yang tak ternilai harganya. Kekayaan alam yang melimpah baik dari dalam perut bumi, di laut, maupun di darat telah menjadi incaran bangsa lain untuk bisa menguasai dan mengeksploitasinya. Tidak heran Portugis, Belanda, dan Jepang menjajah Indonesia selama ratusan tahun hanya karena ingin mengeruk seluruh kekayaan yang dimiliki bangsa Indonesia.

Dari aspek geopolitik, Indonesia terletak di jalur persimpangan dunia sehingga secara politik Indonesia memainkan peran yang cukup strategis dalam percaturan politik internasional. Secara ekonomi Indonesia juga terletak di persimpangan jalur perdagangan dunia sehingga Indonesia juga berperan sangat strategis dalam percaturan ekonomi dunia. Dengan jumlah penduduk sekitar 250 juta, Indonesia dipandang sebagai negara yang sangat 
potensial secara ekonomi baik sebagai tujuan pemasaran produkproduk maupun sebagai tempat investasi. Dari aspek kekayaan bahasa, Indonesia memiliki tidak kurang dari 700 bahasa daerah (vernacular) di seluruh Indonesia mulai bahasa daerah yang penuturnya hanya mencapai ratusan sampai bahasa daerah yang penuturnya mencapai puluhan juta. Semua potensi kekayaan itu membentuk sebuah wawasan yang dinamakan wawasan nusantara. Semua aspek strategis ini jelas sangat menguntungkan posisi Indonesia di mata internasional dan bagi kepentingan nasional bangsa Indonesia.

Dari aspek kebahasaan, Indonesia agak berbeda dengan situasi kebahasaan yang terdapat di negara-negara lain. Kita ambil contoh, negara tetangga Malaysia yang sebetulnya memiliki kemiripan kondisi sosial kemasyarakatan dengan Indonesia.
Di sana masih terjadi tarik ulur dan menjadi perdebatan yang belum tuntas mengenai bahasa nasional mereka, apakah Melayu ataukah bahasa Inggris. Apakah Inggris dipakai di ranah formal, ataukah di ranah informal atau kedua-duanya atau justru Melayu yang harus didahulukan jika berada di situasi formal. Fungsi dan peran kedua bahasa tersebut masih belum jelas. Salah satu bukti bahwa penentuan bahasa nasional mereka belum tuntas adalah adanya protes dari etnis Melayu yang menjadi etnis dominan di Malaysia yang menuntut agar mata pelajaran sains dan matematika yang selama ini menggunakan bahasa pengantar bahasa Inggris diubah ke dalam bahasa Melayu. Protes warga Melayu ini sempat memanas beberapa waktu yang lalu.

Berbeda dengan situasi kebahasaan di Indonesia, meskipun Indonesia memiliki 700 
lebih bahasa daerah (vernacular) dari Sabang sampai Merauke bahasa Indonesia tetap merupakan satu-satunya bahasa nasional yang dimiliki bangsa Indonesia. Keputusan bahwa satu-satunya bahasa nasional dan bahasa persatuan Indonesia adalah bahasa Indonesia sudah selesai dan tuntas sejak dideklarasikan pada tanggal 28 Oktober 1928 yang dikenal dengan peristiwa bersejarah "Sumpah Pemuda". Saat itu semua unsur dan golongan dari berbagai suku dan latar belakang budaya dengan kesadaran penuh berkumpul untuk menyatakan dan mendeklarasikan sebuah bahasa yang kelak akan berperan sangat vital dalam mempersatukan semua elemen di seluruh nusantara. Setelah peristiwa itu, secara de facto dan psikologis bahasa Indonesia telah menjadi semangat dan ruh yang menyatukan segala perbedaan diantara mereka. Kemudian secara de jure bahasa Indonesia resmi sebagai bahasa negara setelah UUD 1945 disahkan yang di dalamnya secara tegas dinyatakan bahwa bahasa Indonesia adalah bahasa negara, yaitu pada Bab XV Pasal 36.

\section{Pembahasan}

\subsection{Bahasa Indonesia sebagai Lingua Franca}

Unesco dalam sebuah publikasi di Paris tahun 1953 mendefinisikan lingua franca sebagai berikut: "a language which is used habitually by people whose mother tongues are different in order to facilitate communication between them." (Wardhaugh, 1986; 55). Lingua franca adalah bahasa yang biasa digunakan oleh masyarakat yang bahasa ibunya berbeda sebagai sarana untuk berkomunikasi. Dalam konteks ini, bahasa Indonesia bagi masyarakat Indonesia yang multikultur dan multietnis berarti juga berfungsi sebagai lingua franca, yaitu sebagai sebuah sistem yang 
menjadi jembatan komunikasi negara bangsa (nation state). bagi penutur-penutur bahasa Bahasa Melayu banyak dipakai daerah yang berbeda-beda. Hal ini juga nampak pada kebijakan politik bahasa nasional yang menyatakan bahwa salah satu fungsi bahasa Indonesia adalah sebagai alat perhubungan antardaerah di Indonesia.

Para pendiri bangsa (founding fathers) telah menentukan jati diri dan nasib bangsanya dengan mengangkat bahasa Melayu menjadi bahasa Indonesia. Keputusan ini dirasa sudah sangat tepat karena bahasa Melayu sudah dipakai sebagai lingua franca di seluruh nusantara selama ribuan tahun sejak abad VII Masehi. Walaupun suku dan bahasa Jawa dominan pada saat itu, yang digunakan sebagai bahasa pengantar dalam hal perdagangan adalah bahasa Melayu. Dengan demikian, penentuan bahasa nasional merupakan puncak kesadaran para pendiri bangsa dalam mendirikan dalam transaksi dan perdagangan yang mempertemukan orang dari berbagai daerah dan memiliki latar belakang budaya dan bahasa yang berbeda-beda. Terbukti pemilihan dan penentuan bahasa Melayu sebagai bahasa asal dari bahasa Indonesia untuk dijadikan bahasa nasional dan persatuan sudah tepat. Di tengah masyarakat yang sangat majemuk dari berbagai latar belakang budaya dan bahasa yang berbeda-beda, bahasa Indonesia telah berhasil memainkan peran dan fungsinya secara tepat yaitu mempersatukan seluruh elemen bangsa dan menyatukan seluruh komponen ke dalam sebuah negara bangsa yang bernama Indonesia.

\subsection{Bilingualisme di Indonesia}

Bilingualisme atau kedwibahasaan (bilingualism) menurut Subyakto-Nababan (1992) harus dibedakan dengan bilingualitas (bilinguality). 
Bilingualisme adalah kebiasaan atau perilaku untuk menggunakan dua bahasa dalam sebuah masyarakat bahasa (speech community), sedangkan bilingualitas adalah kemampuan seseorang memahami dua bahasa. Bilingualisme terjadi pada masyarakat yang bilingual atau bahkan multilingual yaitu masyarakat yang menggunakan dua buah bahasa atau lebih dalam melakukan komunikiasi antaranggota masyarakat tersebut. Sementara bilingualitas lebih mengacu kepada perseorangan, yaitu kemampuan seseorang dalam menggunakan dua bahasa yang berbeda.

Dalam praktiknya para tokoh bahasa masih memunyai pandangan dan pendapat yang berbeda-beda mengenai fenomena bilingualisme ini. Bloomfield dalam Rahardi (2001) mengatakan bahwa bilingualisme adalah fenomena penguasaan bahasa kedua dengan derajat penguasaan yang sama seperti penutur asli. Pandangan lain disampaikan oleh Macnamara (1967) dalam Rahardi (2001) yang mengatakan bahwa tingkat penguasaan bahasa kedua tidak harus sama dengan penguasaan bahasa pertama. Bahkan Haugen (1972) dalam Rahardi (2001) mengatakan bahwa bilingualisme hanyalah pengenalan terhadap bahasa kedua (b2). Hal ini berarti dalam konteks masyarakat Indonesia menurut pandangan Bloomfield, penguasaan bahasa Indonesia sebagai bahasa kedua harus sama dengan kemampuan bahasa pertama yaitu bahasa daerah (vernacular atau tribal language) sementara menurut pandangan kedua kemampuan bahasa Indonesia tidak harus sama seperti penguasaan terhadap bahasa daerah sebagai bahasa pertama masyarakat Indonesia.

Bilingualisme atau multilingualisme pada tataran tertentu bagi sebagian orang masih 
menjadi hal yang tidak umum dan terkesan agak aneh. Bagi mereka 'kemampuan' para orang-orang bilingual ini dalam menggunakan dua bahasa kadang-kadang masih dianggap sesuatu yang negatif karena menurut mereka biasanya orang-orang atau masyarakat yang bilingual adalah para imigran atau pendatang dengan segala permasalahan hidup mereka dan anak-anak hasil kawin campur (mix marriage). Coba simak pendapat dari Wardhaugh (1986: 94) berikut ini:

"...to the extent that
bilingual and
multilingual individuals
may appear to be
'unusual'... feeling of
superiority in that many
such people are not
'native' to the
culture... and such
marking is not always
deemed to be a positive
attribute."

Pada konteks saat itu terutama di negara-negara Barat fenomena kawin campur masih belum biasa salah satu faktornya adalah adanya ego dan superioritas ras tertentu yang menganggap bahwa suku dan ras mereka lebih unggul dari yang lain sehingga mereka hanya berhak berpasangan denga sesama ras mereka dan tidak bisa campur dengan ras lain yang mereka anggap lebih rendah. Oleh sebab itu, orang-orang bilingual dan multilingual tidak selalu memunyai citra yang positif di mata masyarakat.

$$
\text { Dalam }
$$

konteks

keindonesiaan

kondisi

bilingualisme direpresentasikan oleh pemakaian bahasa pertama (b1) dan bahasa kedua (b2). Dalam situasi dan keadaan tertentu bilingualisme ini berubah menjadi multilingualisme (multingualism) dengan adanya penambahan pemakaian bahasa asing (b3) selain b1 dan b2 terutama hal ini sering terjadi di kota-kota besar yang sebagian besar penduduknya adalah golongan terdidik (highly educated) dan memunyai akses 
yang sangat besar ke dunia ini selain berfungsi sebagai alat internasional. Golongan komunikasi antaranggota masyarakat ini sering dilabeli kelompok juga berfungsi sebagai dengan istilah keluarga modern penanda identitas kedaerahan.

yang salah satu cirinya adalah Bahasa kedua (b2) adalah menonjolnya pemakaian bahasa bahasa Indonesia yang secara asing terutama bahasa Inggris, formal telah dideklarasikan sejak baik secara personal maupun tanggal 28 Oktober 1928 dalam penerapan dalam keluarga. sebuah peristiwa Sumpah Pemuda. Bahasa pertama atau Di situ, bahasa Indonesia telah bahasa ibu (mother tongue) di diakui sebagai bahasa nasional Indonesia adalah bahasa yang Indonesia dan dipakai secara diperoleh anak pertama kalinya dari kedua orang tua mereka. Jika demikian, bahasa pertama orang Indonesia bisa berupa bahasa daerah (vernacular) atau bisa juga bahasa Indonesia (lingua franca). Petyt seperti yang dikutip oleh Wardhaugh (1986; hal. 37) mengatakan bahwa bahasa daerah atau vernacular adalah bahasa yang ditransmisikan dari orang tua kepada anak yang dipakai sebagai media komunikasi utama, "a form of speech transmitted from parent to child as a primary medium of communication". Bahasa daerah resmi dalam bidang pendidikan dan pemerintahan. Dalam konteks ini, bahasa Indonesia juga menjadi alat perhubungan antarsuku bangsa di Indonesia di samping sebagai penanda identitas nasional kebangsaan dan lambang kebanggaan nasional.

Sejak bahasa Indonesia dideklarasikan pada tahun 1928 dan selanjutnya disusun dalam sebuah perencanaan bahasa yang dimanifestasikan dalam bentuk kebijakan politik bahasa nasional, penggunaan bahasa daerah sebagai bahasa pertama dan bahasa 
Indonesia sebagai bahasa kedua bahasa Indonesia dipelajari di berjalan beriringan. Masing- sekolah-sekolah dan dari masing memiliki ranah lingkungan tertentu.

pemakaian, peran, dan fungsi Pada kasus-kasus tertentu sendiri sehingga tidak saling terutama pada masa-masa menggantikan fungsi, peran dan sekarang batas antara bahasa kedudukan setiap bahasa tersebut. pertama (b1) dalam hal ini bahasa Dalam interaksi dengan kelompok daerah dan bahasa kedua (b2) sosial dan keluarga fungsi semakin tidak jelas. Kekuatan dan komunikasi dijalankan oleh status bahasa Indonesia sebagai bahasa daerah sementara dalam bahasa yang dianggap lingkungan pendidikan dan merepresentasikan kemajuan dan pemerintahan fungsi komunikasi kesempatan akses ke dalam dunia dijalankan oleh bahasa Indonesia. kerja dan ekonomi yang lebih luas Masyarakat Indonesia semakin menggantikan fungsi dan kecuali sebagian di daerah-daerah peran bahasa daerah. Menurut yang terpencil yang belum hasil penelitian yang pernah tersentuh dunia pendidikan dan dilakukan penulis terhadap kemajuan seperti di pedalaman responden, yaitu keluarga muda di Papua, Kalimantan umumnya Jawa Timur hanya 13 persen dari telah menguasai paling tidak dua 15 responden yang tidak bergeser bahasa, yaitu bahasa daerah bahasa. Keluarga responden (native vernacular) dan bahasa lainnya sudah bergeser bahasa dari Indonesia (second language). bahasa daerah sebagai bahasa Bahasa daerah diperoleh dari pertama menjadi bahasa Indonesia bahasa ibu orang tua yang dipakai sebagai bahasa pertama bagi anakdalam kehidupan sehari-hari anak mereka. Sebagian besar sebagai bahasa pengantar dan alasan mereka bergeser bahasa 
adalah secara umum agar lebih memudahkan si anak dalam bergaul di sekolah dan masyarakat dan berharap kelak akan mendapatkan akses yang lebih baik dalam bidang ekonomi maupun dunia kerja jika anak mereka bisa berbahasa Indonesia sejak awal.

\section{Dalam situasi yang} diglosik bahkan multiglosik dengan adanya bahasa asing di antara bahasa daerah dan bahasa Indonesia, sudah barang tentu ada tarik menarik dalam hal kekuatan dan pengaruh bahasa. Dalam kehidupan masyarakat Indonesia kelas menengah, bahasa Indonesia telah menjadi bahasa yang lebih prestisius dibandingkan dengan bahasa daerah sehingga masyarakat golongan ini berusaha untuk menguasai bahasa kedua ini dengan lebih baik dan lebih awal. Akibatnya, pengembangan bahasa Indonesia bagi golongan masyarakat ini memunyai dorongan yang positif.
Bagi masyarakat kelas bawah yang salah satunya dicirikan oleh tingkat pendidikan yang agak kurang dan tingkat ekonomi yang relatif kurang baik, bahasa pertama merupakan bahasa utama sehingga orientasi untuk menguasai bahasa Indonesia sejak dini kurang atau tidak ada sehingga pengembangan bahasa Indonesia bagi golongan ini kurang mendapat dukungan. Biasanya masyarakat yang tinggal di pelosok-pelosok desa yang agak terpencil yang akses terhadap informasi dan kemajuan sangat kurang.

Yang terakhir adalah masyarakat kelas atas, yaitu masyarakat yang secara pemikiran dan status sosial sudah sangat maju dan mapan. Ciri-cirinya adalah tingkat pendidikan yang sudah tinggi dan tingkat ekonomi yang sudah mapan. Satu hal lagi bahwa repertoire bahasa mereka bertambah dengan penguasaan bahasa asing. Pemikiran mereka 
sudah mengglobal sehingga salah satu negara yang tuntutan akan kemampuan penduduknya bilingual atau berbahasa asing semakin tinggi bahkan multilingual. Hal ini agar tidak ketinggalan zaman. terbukti dengan banyaknya bahasa Untuk masyarakat yang terakhir daerah (vernacular atau tribal ini, pengembangan bahasa language) yang terdapat di Indonesia agak kurang Indonesia. Menurut survei ada memperoleh dukungan yang sekitar 700 bahasa daerah yang positif karena adanya sikap bahasa ada di Indonesia.

(language attitude) yang kurang Masih menurut Holmes positif terhadap bahasa Indonesia. (2001:73): "They acquire a Mereka lebih memosisikan bahasa number of language because they asing lebih utama daripada bahasa need them for different purposes Indonesia.

\subsection{Bilingualisme $v s$}

Pengembangan Bahasa

\section{Indonesia}

Sejalan dengan apa yang dikatakan oleh Holmes (2001:73) bahwa lebih dari separuh penduduk dunia adalah bilingual atau menguasai paling tidak dua bahasa dan banyak penduduk yang bahkan multilingual atau menguasai lebih dari dua bahasa. "over half the world's population is bilingual and many people are multilingual". Indonesia adalah in their everyday interactions". Mereka menguasai sejumlah bahasa karena mereka memerlukannya untuk tujuantujuan yang berbeda-beda dalam kehidupan mereka sehari-hari. Dalam konteks inilah, para pendiri bangsa dinilai cerdik dan berwawasan kebangsaan yang luas dengan melahirkan bahasa persatuan yaitu bahasa Indonesia. Dalam perkembangan selanjutnya, yaitu dalam kebijakan politik bahasa nasional peran, fungsi dan kedudukan bahasa Indonesia, 
bahasa daerah, dan bahasa asing ditentukan sehingga masingmasing memunyai domain pemakaian sendiri-sendiri. Bahasa daerah dipakai dalam ranah informal kekeluargaan, bahasa Indonesia digunakan dalam ranah formal resmi pendidikan dan pemerintahan, dan bahasa asing hanya dalam konteks pergaulan internasional.

Situasi di atas mirip dengan situasi diglosik seperti yang diutarakan oleh Fergusson (1959:336) dalam Wardhaugh (1986:87) sebagai berikut.

"Diglossia is a relatively stable language situation in which, in addition to the primary dialects of the language (which may include a standard or regional standards), there is a very divergent, highly codified (often grammatically more complex) superposed variety, the vehicle of a large and respected body of written literature, either of an earlier period or in another speech community, which is learned largely by formal education and is used for most written and formal spoken purposes but is not used by any sector of the community for ordinary conversation."

Bahwa bahasa daerah, bahasa Indonesia, dan bahasa asing memunyai wilayah pemakaian sendiri-sendiri. Namun demikian, dalam perkembangannya, seiring dengan semakin majunya tingkat pendidikan masyarakat Indonesia mulailah terjadi interaksi dan kontak bahasa (language contact) dan akhirnya mulai terjadi kebocoran situasi diglosik tadi. Ranah keluarga yang menjadi wilayah pemakaian bahasa daerah telah dimasuki oleh pemakaian bahasa Indonesia. Demikian juga ranah pendidikan yang seharusnya menjadi domain pemakaian bahasa Indonesia mulai dimasuki oleh bahasa asing (Inggris) sebagai bahasa pengantar. Hal ini terbukti dengan semakin banyaknya Rancangan Sekolah Bertaraf Internasional (RSBI). Menurut Wardhaugh 
(1986:90) dalam Wijana

(2006:35) bahwa keinginan yang besar untuk menciptakan bahasa persatuan merupakan faktor yang dominan dalam melemahkan situasi diglosia di Indonesia.

Dalam penelitian yang pernah dilakukan oleh penulis tentang faktor yang memengaruhi adanya pegeseran bahasa (language shift) sebanyak 13 persen pasangan keluarga muda yang berasal dari etnis Jawa dan Madura telah memutuskan untuk bergeser bahasa ke bahasa Indonesia dalam komunikasi dengan anak-anak mereka.

Dalam perspektif pengembangan bahasa Indonesia, kondisi kedwibahasaan masyarakat Indonesia sangat menguntungkan. Hal ini karena paling tidak, ada dua keuntungan yang diperoleh, yaitu pertama status dan kedudukan bahasa Indonesia sebagai bahasa nasional yang semakin meningkat, dan kedua semakin banyak kosakata yang bisa disumbangkan oleh bahasa daerah kepada bahasa Indonesia.

Dalam situasi masyarakat bahasa yang bilingual dan multilingual, kontak bahasa adalah fenomena yang tidak bisa terhindarkan. Saling pengaruh antara bahasa daerah, bahasa Indonesia, dan bahasa asing terusmenerus berlangsung dalam wujud interferensi bahasa baik dalam tata bunyi maupun struktur tata bahasanya. Karena kondisi sosial masyarakat yang menuntut adanya sebuah bahasa yang mantap dan adanya motivasi untuk menyatukan diri dalam wadah negara Indonesia maka status dan kedudukan bahasa Indonesia semakin tinggi. Bahasa Indonesia telah menjadi variasi bahasa tinggi (high variety) $(\mathrm{H})$ dan bahasa suku atau daerah (tribal language) adalah bahasa rendah (low variety) (L).

Kontak bahasa adalah sebuah keniscayaan antara bahasa 
daerah dengan bahasa Indonesia dan bahasa asing. Pengembangan bahasa Indonesia masih kadangkadang terkendala oleh kebijakankebijakan dari pemda sendiri. Konsep otonomi daerah ternyata tidak cukup ditafsirkan dan diartikan secara benar oleh pemimpin-pemimpin daerah.

Otonomi daerah ternyata alih-alih memajukan dan mengembangkan potensi daerah, malah menciptakan raja-raja kecil di daerah. Arah pengembangannya semakin mempertinggi sentimen kedaerahan dan primordialisme. Salah satu buktinya adalah semakin banyaknya daerah-daerah yang ingin membentuk pemerintahan dan provinsi sendiri meskipun belum melalui studi kelayakan untuk memastikan apakah daerah tersebut sudah layak dan mampu membentuk pemerintahan sendiri.

\section{Penutup}

Masyarakat

Indonesia

yang sebagian

besar dwibahasawan (bilingual) bahkan untuk kalangan tertentu multibahasawan dengan adanya bahasa asing telah memberikan dinamika yang sangat tinggi dalam hal pengembangan bahasa Indonesia. Bahasa Indonesia telah menempati posisi yang cukup strategis baik sebagai bahasa nasional yang berfungsi untuk mempersatukan seluruh elemen bangsa maupun potensi sebagai bahasa regional.

Peran dan kedudukan bahasa Indonesia di tengah keberagaman dan keanekaragaman budaya dan bahasa di Indonesia semakin meningkat. Sejalan dengan upaya pemartabatan bahasa Indonesia dan pelestarian bahasa daerah serta pembinaan bahasa asing seperti yang dilakukan oleh Pusat Bahasa, bahasa Indonesia semakin mendapatkan legitimasi di mata 
masyarakat Indonesia maupun di Indonesia terdapat ratusan internasional.

bahasa

daerah

yang

Kondisi masyarakat merepresentasikan

keragaman

Indonesia yang multikultur dan suku dan budaya yang ada adalah bilingual dengan bahasa etnis fakta yang harus disyukuri karena yang jumlahnya mencapai tujuh bahasa daerah bisa mendukung ratusan tidak menghalangi bangsa Indonesia untuk mengembangkan bahasa Indonesia sebagai bahasa nasional dan sekaligus sebagai identitas nasional masyarakat Indonesia. Kekayaan adat istiadat dan budaya alih-alih menjadi penghalang bahkan menjadi karakter dan warna yang kuat bagi bahasa Indonesia sebagai lingua franca di seluruh kepulauan nusantara.

\section{Bahasa-bahasa} yang perencanaan dan pengembangan bahasa nasional yaitu bahasa Indonesia misalnya dalam hal pembentukan dan pengembangan kosakata baru dalam bahasa Indonesia. Demikian pula dengan keberadaan bahasa asing yang menjadi sebuah keniscayaan akibat semakin dalamnya masuk ke pergaulan internasional dan semakin majunya ilmu pengetahuan dan teknologi

terdapat di Indonesia sedang mencari posisi dan peran yang tepat untuk masing-masing. Adanya interferensi (interference), alih kode (code switch), dan campur kode (code mix) adalah sebuah dampak yang tak terhindarkan akibat adanya kontak bahasa (language contact). Bahwa 
Daftar Pustaka

Anwar, Khaidir. (1990). Fungsi dan Peranan Bahasa, Sebuah Pengantar. Yogyakarta: Gajah Mada University Press.

Holmes, Janet. (2001). An Introduction to Sociolinguistics. England: Longman

Rahardi, Kunjana. (2001). Sosiolinguistik: Kode dan Alih Kode. Yogyakarta: Pustaka Pelajar.

Subyakto, Sri Utari Nababan. (1992). Psikolinguistik Sebuah Pengantar. Jakarta: Gramedia Pustaka Utama.
Susanto, Djoko. (2008). Codeswitching Indonesian in Religious Discussion: a Sociolinguistic Perspective. Malang: UIN Malang Press.

Tadmor, Uri. (2007). Kontroversi Asal-Usul Bahasa MelayuIndonesia. Makalah ini untuk disajikan dalam PELBA ke-18. Jakarta: Unika Atmajaya.

Wardhaugh, Ronald. (1986). An Introduction to Sociolinguistics. OxfordUK: Basil Blackwell..

Wijana, I Dewa Putu \& R, Muhammad. (2006). Sosiolinguistik: Kajian Teori dan Analisis. Yogyakarta: Pustaka Pelajar. 